\title{
COVID19 Pandemic and the use telepsychiatry in child mental health practices
}

\author{
Hande Ayraler Taner ${ }^{1}$ \\ ${ }^{1}$ Assis. Prof., Baskent University Faculty of Medicine, Department of Child and Adolescent Psychiatry, Ankara, Turkey \\ https://orcid.org/0000-0003-2106-7928
}

\section{TO THE EDITOR}

The COVID 19 pandemic which started at the end of 2019 has affected the whole world. Children with mental problems and their families have had difficulty in accessing hospitals and psychiatric clinics due to the concern with being infected with the virus. As a solution to this difficult situation one of the methods most frequently applied by the professionals working in the field of child mental health is telepsychiatry .In a recent study published just before the pandemic it was suggested that although child mental health professionals has positive attitudes towards technology, they have doubts about the available resources and their safety, reliability and privacy (1). For child mental health professionals who have suspicions about the use of technology in clinical practice this pandemic process was both challenging and informative.

Telepsychiatry, which means providing psychiatric support to people outside a clinic, office or hospital through videoconferencing or other tecnologies, has been used more commonly during the pandemic period (2). However, the spreading telepsychiatry implementation has brought with it problems, such as, difficulty in keeping doctor-patient confidentiality and data safety (3). There are no regulatory authorities for monitoring telepsychiatry implementation. Lacking regulation services may cause psychiatry implementation provided by incompetent people under the name of "telepsychiatry". Also in many places, public conferencing tools such as Zoom and Skype are used (4). This brings the risk of sharing data in an unsafe environment and damaging the privacy of the patient- physician relationship. In addition, there are is continuing discussions of how or whether to reimburse for telepsychiatry. A legal regulation was put in placein relation to telepsychiatry implementation and reimbursement in the U.S.A in March, 2020 (5).Yet, there are no legal regulations in most countries. Unregistered practices may legally put mental health professionals at risk in the future.

Implementation of child focused telepsychiatry that includes psychiatric examination with the child and his/her family, evaluation of cognitive processes, neuropsychological tests, child and family observation, game therapy and other psychotherapies and psychotropic drug prescription dates back to the 1970s (6). In a study, it was suggested that diagnoses and treatments provided in child psychiatry assesments during computer-based videoconference showed a $96 \%$ correspondence to visits made in person. In the same study, a total of $91 \%$ of the parents suggested that they would prefer videoconferencing instead of going long distances to an office (7). Although there are published studies about the efficacy of telepsychiatry practices in child and adolescent psychiatry, reliability of some diagnostic interviews and the use of some neuropsychological tests by video-conferencing; in the literature there is limited information about which patients to be chosen, whether it would be beneficial for which mental disorders or not, which methods to be used and the use of psychological tests $(8,9)$. In a case report of a patient diagnosed with Asperger Syndrome who did not prefer face-toface visit, symptoms were relieved in videoconference-based visits and the patient was then reported to accept face-to-face visit (10). Similar to the Asperger patient some mental health disorders 
(such as social anxiety disorder, autism spectrum disorder, obsessive compulsive disorder), may benefit from telepsychiatry beyond the face-to-face visit. The way of using telepsychiatry applications varies according to the age of the child, and the child's cognitive abilities. Young children and children and adolescents with cognitive disabilities find it difficult to use technological tools without their parents. Even in interviews with adolescent patients who use technology comfortably, family members can intervene in the online interview. These intrusions can damage the therapeutic relationship with the patient and negatively affect the success of the therapy. Neuropsychological tests using various materials can be difficult to apply in videoconferencing interviews. This can affect the reliability of the test. Tests prepared specifically for a videoconference interview and whose validity and reliability studies have been carried out can help in this issue. To answer all these questions comprehensive studies are required on all these issues. People working in the field of technology and mental health need to foster closer collaboration to ensure appropriate, and ethical tools to foster telepsychiatry.

The pandemic has provided an opportunity to introduce innovation into mental health care. This

\section{REFERENCES}

1. Cliffe B, Croker A, Denne M, Stallard P. Clinicians' use of and attitudes towards technology to provide and support interventions in child and adolescent mental health services. Child Adolesc Ment Health [Internet]. 2020 May 1;25(2):95-101. Available from: https://doi.org/10.1111/camh.12362

2. Shore JH, Schneck CD, Mishkind MC. Telepsychiatry and the Coronavirus Disease 2019 Pandemic-Current and Future Outcomes of the Rapid Virtualization of Psychiatric Care. JAMA Psychiatry [Internet]. 2020 May 11; Available from: https://doi.org/10.1001/jamapsychiatry.2020.1643

3. Fegert JM, Vitiello B, Plener PL, Clemens V. Challenges and burden of the Coronavirus 2019 (COVID-19) pandemic for child and adolescent mental health: a narrative review to highlight clinical and research needs in the acute phase and the long return to normality. Child Adolesc Psychiatry Ment Health. 2020;14:1-11.

4. Soron TR, Shariful Islam SM, Ahmed HU, Ahmed SI. The hope and hype of telepsychiatry during the COVID-19 pandemic. The lancet Psychiatry [Internet]. 2020 Aug;7(8):e50-e50. Available from: https://pubmed.ncbi.nlm.nih.gov/32711713

5. Chen JA, Chung W-J, Young SK, Tuttle MC, Collins MB, Darghouth SL, et al. COVID-19 and telepsychiatry: Early outpatient experiences and implications for the future. Gen Hosp Psychiatry [Internet]. $2020 \mathrm{Jul}$ 9;66:89-95. Available from: https://pubmed.ncbi.nlm.nih.gov/32750604 may result in lasting changes to the delivery of care and open up new possibilities for care. Studies, especially on the field of child's mental health, will expand our horizons and provide needed guidance for responsible care.

Funding: The author received no specific grant from any funding agency in the public, commercial, or not-for-profit sectors.

Conflict of interest: The author declares that there is no conflict of interest.

Acknowledgements: The author would like to thank Prof Myron Belfer for reading and commenting on the article

Correspondence address: Assis. Prof., Hande Ayraler Taner, Baskent University Faculty of Medicine, Department of Child and Adolescent Psychiatry Ankara, Turkey h_ayraler@hotmail.com
6. Straker N, Mostyn P MC. The use of two-way TV in bringing mental health services to the inner city. Am J Psychiatry [Internet]. 1976 Oct 1;133(10):1202-5. Available from: https://doi.org/10.1176/ajp.133.10.1202

7. Elford, R., White, H., Bowering, R., Ghandi, A., Maddiggan, B., \& John, K. S. (2000).A randomized, controlled trial of child psychiatric assessments conducted using videoconferencing. J Telemed Telecare [Internet]. 2000 Apr 1;6(2):73-82. Available from: https://doi.org/10.1258/1357633001935086

8. Reese RM, Jamison R, Wendland M, Fleming K, Braun MJ, Schuttler JO, et al. Evaluating interactive videoconferencing for assessing symptoms of autism. Telemed e-Health. 2013;19(9):671-7.

9. Stain HJ, Payne K, Thienel R, Michie P, Carr V, Kelly B. The feasibility of videoconferencing for neuropsychological assessments of rural youth experiencing early psychosis. J Telemed Telecare. 2011;17:328-31.

10. Clarke CS. Telepsychiatry in Asperger's syndrome. Ir J Psychol Med [Internet]. 2017/07/10. 2018;35(4):325-8. Available from: https://www.cambridge.org/core/article/telepsychiatry-inaspergers-syndrome/F37C45A68AFA9B181803A2B828008F8A 